\title{
Antimicrobial Activities of Aframomum Melegueta (Alligator Pepper)
}

\author{
Doherty, V.F. (Corresponding author) \\ Department of Biological Sciences, Yaba College of Technology \\ P.M.B 2011, Yaba Lagos, Nigeria \\ Tel: 234-803-310-7074Ｅ-mail: funmilayodoherty@yahoo.co.uk. \\ Olaniran, O.O \\ Department of Biological Sciences, Yaba College of Technology \\ P.M.B 2011, Yaba Lagos, Nigeria \\ E-mail: kemo4real77@yahoo.com \\ Kanife U.C. \\ Department of Biological Sciences, Yaba College of Technology \\ P.M.B 2011, Yaba Lagos, Nigeria \\ E-mail: claribeb_ife@yahoo.com
}

\begin{abstract}
Antibacterial activity of Aframomum melegueta was tested on salmonella spp, Escherichia coli, Shigella spp and klebsiella spp. Ethanol and distilled water were used as solvents for the extraction of the plant. The ethanolic extract was found to be most effective at high concentration of $50 \mathrm{mg} / \mathrm{ml}$ on all the isolates. The zones of inhibition of klebsiella spp, salmonella spp, E. coli and Shigella spp are $30 \mathrm{~mm}, 15 \mathrm{~mm}, 20 \mathrm{~mm}$, and $15 \mathrm{~mm}$ respectively with ethanolic extract. The aqueous extract was found to be less effective when compared with ethanolic extract.

The phytochemcial analysis carried out on Aframomum melegueta revealed the presence of alkaloids, tannins, saponin, steroids, cardiacglycoside, flavonoid, terpenoids and phenol. The presence of these phytochemcials support the use of this plant as antimicrobial agent. Aframomum melegueta can therefore be used as antimicrobial agent against the groups of Enterobacteriaceae tested.
\end{abstract}

Keywords: Antimicrobial activity, Aframomum, Terpenoids, Phytochemical

\section{Introduction}

The use of traditional medicine is wide spread throughout the world. The term, traditional medicine is interchangeably used with herbal medicine and natural medicine (Hazan and Atta, 2005). Since antiquity, man has used plants to treat common infectious diseases and even long before mankind discovered the existence of microbes; the idea that certain plants had healing potential was well accepted (Rios and Recio, 2005).A medicinal plant is any plant which, in one or more of its organs, contains substances that can be used for therapeutic purpose or which are precursors for the synthesis of useful drugs. A number of plants have been used in traditional medicine for many years due to their antimicrobial properties(Sofowora, 1993). Specifically, the medicinal value of these plants lies in some chemical substances that produce a definite physiological action on the human or animal body (Edeoga et al., 2005). The most important of these bioactive constituents which are mainly secondary metabolites are alkaloids, flavonoids, tannins and phenolic compounds. These phytochemicals are toxic to microbial cells.

Aframomum melegueta is a tropical herbaceous perennial plant of the genus Aframomum belonging to the family zingiberaceae (ginger family) of the angiosperms in the Kingdom plantae. The seeds have pungent peppery taste due to aromatic ketones (Galal,1996, Tackie el. al,1975). It is a plant with both medicinal and nutritive values, found commonly in rain forest. It is widely spread across tropical Africa including Nigeria, Liberia, Sierra Leone, Ghana, Cameroon, Cote D' ivoire and Togo. The phytochemicals obtained from the seed of Aframomum melegueta has been used for years in the treatment of infectious diseases. The grains of Aframomum melegueta 
possess active ingredients that may be exploited for local development of antimicrobials (Oyegade,1999). The presence of phenolic compounds in the seed of Aframomum melegueta indicates that this plant is an antimicrobial agents and this is because phenols and phenolic compounds have been extensively used in disinfections and remain the standard with which other bactericides are compared (Okwu, 2001b). Extracts from the seed of Aframomum melegueta with have potent antiseptic or bactericidal properties, have therefore been used in treating wounds and preventions of infections (Okwu, 2004). According to (Oladunmoye, 2007). Aframomum melegueta was tested for antimicrobial effects on five pathogenic bacteria which include Bacillus cereus, Staphylococcus aureus, Escherictaia coli, Salmonella typhi and klebsiella pneumonia. The plant extract of Aframomum melegueta was found inhibitory to the growth of Klebsiella pneumonia and Salmonella typhi. The findings revealed that extract from Aframomum melegueta contain phytochemicals which offer an enormous potential as bio control of these pathogens and source of antimicrobial agents of therapeutic importance. The objectives of this study is therefore to carry out phytochemical analysis on the seed extracts, determine the minimum inhibitory concentration (MIC) of the crude extracts of the seeds and to ascertain the antimicrobial property of the crude extract

\section{Materials and methods}

\subsection{Collections of samples}

The sample was bought from Oyingbo market in Ebute metta, Lagos, Nigeria. The variety was chosen because it is widely used in all parts of the country as spice, condiments and in soup making.

\subsection{Preparation of sample}

400 grammes of the sample were dried at room temperature for one week. After drying, 350 grammes were obtained. The sample was ground and put into a container and it was labeled and stored in preparation for the extraction process.

\subsection{Sterilization}

Autoclavable materials such as agar and broth were aseptically sterilized in an autoclave at $121^{\circ} \mathrm{C}$ for 15 minutes.Petri dishes, beakers, McCartney bottles, pipette, test tubes, filter papers and other metal apparatus such as spatula and forceps were sterilized using hot air oven at a temperature of $160^{\circ} \mathrm{C}$ for 1 hour. The wire loops were sterilized by heating in the blue flame of the bunsen burner until red-hot and allowed to cool before using $70 \%$ alcohol to swab the work bench area to prevent contamination. The process was carried out aseptically.

\subsection{Extraction procedure}

The extraction was done using soaking method. The ground sample was extracted using water and ethanol as solvent. $100 \mathrm{~g}$ of the powdered sample was extracted with $1000 \mathrm{ml}$ of distilled water while $100 \mathrm{~g}$ of the sample was extracted with $1000 \mathrm{ml}$ of $70 \%$ ethanol. The sample was soaked overnight for 24 hours. After 24 hours, the sample was filtered ten times with muslin cloth and the extract was collected in a round bottom flask, filtered and concentrated using a rotary evaporator and then oven dried at $70 \%$.

\subsection{Preparation of culture media}

All culture media were prepared according to manufacturers' instructions and autoclaved at $121^{\circ} \mathrm{C}$ for 15 mins.

\subsection{Preparation of organisms}

Serial dilution was carried out on the isolates collected from Microbiology Department of Lagos State University Teaching Hospital, Idi-Araba Lagos, Nigeria and $10^{-4}$ of the serial dilution was used for the sensitivity testing.

\subsection{Reconstitution of extract}

The dried extracts were reconstituted by dissolving $5 \mathrm{~g}$ each of the extract in $50 \mathrm{ml}$ ethanol and $50 \mathrm{ml}$ distilled water. The solution was filtered using the sterile whatman no1 filter paper. The stock solution was sterilized by filtration through filter paper to remove impurities and other contaminants. The stock solution was further dissolved at different concentration and it was then stored in sterile universal bottles and refrigerated for further analysis.

\subsection{Antimicrobial screening for reconstituted extract}

Two methods were employed for the antimicrobial testing which are the, Agar diffusion method and Disc diffusion method.

\subsubsection{Agar diffusion method}

The antimicrobial screening of the ethanolic extract was done as described by Lino and Deogracious (2006). 
Nutrient agar was poured in sterile Petri dishes and was allowed to solidify. $1 \mathrm{ml}$ of the test culture was dropped on the solidified agar and the organism was spread all over the surface of the agar using a spreader. Wells of approximately $5 \mathrm{~mm}$ in diameter were made on the surface of the agar medium using a sterile cork borer. The plates were turned upside down and the wells labeled with a marker. Each well was filled with $0.2 \mathrm{ml}$ of the extract. Streptomycin disc was used as control for the cultures. The plates were incubated aerobically at $37^{0} \mathrm{c}$ for 24 hours. Sensitivity of the organisms to the extract was recorded

\subsubsection{Disc diffussion method}

The locally prepared sterile discs were soaked in the water extract for some hours and nutrient agar medium was poured in sterile Petri Dishes and it was allowed to solidified. $1 \mathrm{ml}$ of the test organisms was placed on the solidified agar and it was spread all over the surface of the agar. The soaked disc was picked using sterile forceps and it was dropped on the surface of the agar. The plates were incubated at $37^{\circ} \mathrm{C}$ for 24 hours. Sensitivity of the organisms was recorded.

\subsection{Phytochemical analysis}

Phytochemcial screening was carried out on the obtained plant extracts, according to Okwu, (2005).

\subsubsection{Qualitative analysis of the constituents. Test for tannins}

About $0.5 \mathrm{~g}$ of the dried powdered sample was boiled in $20 \mathrm{ml}$ of water in a test tube and then filtered. A few drops of $0.1 \%$ ferric chloride was added and observed for brownish green or a blue black colouration.

\subsubsection{Test for phlobatannin}

An aqueous extract of the plant sample was boiled with $1 \%$ aqueous hydrochloric acid and deposition of a red precipitate was taken as evidence for the presence of phlobatannins.

\subsubsection{Test for saponins}

About $2 \mathrm{~g}$ of the powdered sample was boiled in $20 \mathrm{ml}$ of distilled water in a water bath and filtered. $10 \mathrm{ml}$ of the filtrate was mixed with $5 \mathrm{ml}$ of distilled water and shaken vigorously for a stable persistent froth. The frothing was mixed with 3 drops of olive oil, shaked vigorously and then observed for the formation of emulsion.

\subsubsection{Test for flavonoids}

$5 \mathrm{ml}$ of $10 \%$ dilute ammonia solution was added to a portion of the aqueous filtrate of the plant extract, followed by addition of concentrated $\mathrm{H}_{2} \mathrm{SO}_{4}$. A yellow coloration observed in the extract indicated the presence of flavonoid.

\subsubsection{Test for Cardiac Glycosides}

$5 \mathrm{ml}$ of the extract was treated with $2 \mathrm{ml}$ of glacial acetic acid containing I drop of ferric chloride solution $(0.1 \%)$. This was underlayed with $1 \mathrm{ml}$ of concentrated $\mathrm{H}_{2} \mathrm{SO}_{4}$. A brown ring of the interface indicated a deoxysugar characteristics of cardenolides. A violet ring may appear below the brown ring, while in the acetic layer, a greenish ring may form just gradually throughout thin layer.

\subsubsection{Determination of total phenols by spectrophotometer methods}

The fat free sample was boiled with $50 \mathrm{ml}$ of ether for the extraction of the phenolic component for 15 minutes. $5 \mathrm{ml}$ of the extract was pipetted into a $50 \mathrm{ml}$ flask and then $10 \mathrm{ml}$ of distilled water was added. $2 \mathrm{ml}$ of ammonium hydroxide solution and $5 \mathrm{ml}$ of concentrated amylachohol were made up to mark and left to react for $30 \mathrm{~min}$. Colour development was measured at $505 \mathrm{~nm}$.

\subsubsection{Alkaloid determination using Harborne (1973) method}

$5 \mathrm{~g}$ of the sample was weighed into a $250 \mathrm{ml}$ beaker and $200 \mathrm{ml}$ of $10 \%$ acetic acid in ethanol was added and covered and allowed to stand for 4 hours. This was filtered and the extract was concentrated on a water bath to one quarter of the original volume. Concentrated ammonium hydroxide was added drop wise to the extract until the precipitation was complete. The whole solution was allowed to settle and the precipitate collected and washed with dilute ammonium hydroxide and then filtered. The residue is the alkaloid, which was dried and weighed.

\subsubsection{Tannin determination by Van-Burden and Robinson method (1981)}

$500 \mathrm{mg}$ of the sample was weighed into a $50 \mathrm{ml}$ and shaken for 1 hour in a mechanical shaker. This was filtered into a $50 \mathrm{ml}$ volumetric flask and made up to the mark. Then $5 \mathrm{ml}$ of the filtered was pipetted out into a test tube and mixed with $2 \mathrm{ml}$ of $0.1 \mathrm{M} \mathrm{Fecl}_{3}$ in $0 . \mathrm{IM} \mathrm{HCl}$ and $0.008 \mathrm{~m}$ potassium Ferrocyanide. The absorbance was measured at $120 \mathrm{~nm}$ within $10 \mathrm{~min}$. 


\subsubsection{Saponin determination}

The method used was that of Obadoni and Ochuko (2001). Twenty grammes of ground samples was put into a conical flask and $100 \mathrm{ml}$ of $20 \%$ aqueous ethanol was added. The samples were heated over a hot water bath for 4 hours with continuous stirring at about $55^{\circ} \mathrm{C}$. The mixture was filtered and the residue re-extracted with another $200 \mathrm{ml} 20 \%$ ethanol. The combined extracts were reduced to $40 \mathrm{ml}$ over water bath at about $90^{\circ} \mathrm{C}$. The concentrate was transferred into a $250 \mathrm{ml}$ separatory funnel and $20 \mathrm{ml}$ of diethyl ether was added and shaken vigorously.

The aqueous layer was recovered while the ether layer was discarded. The purification process was repeated. Sixty millilitre $(60 \mathrm{ml})$ of $\mathrm{n}$-butanol was added to the extracts and washed twice with $10 \mathrm{ml}$ of 55 aqueous sodium chloride. The remaining solution was heated in a water bath. After evaporation, the extracts were dried in the oven to a constant weight, and percentage saponin content determined.

\subsubsection{Flavonoid determination by the method of Boham and Kocipaiabyazan (1974)}

Ten grammes $(10 \mathrm{~g})$ of the plant sample was extracted repeatedly with $100 \mathrm{ml}$ of $80 \%$ aqueous methanol at room temperature. The whole solution was filtered through Whatman filter paper No. $42(125 \mathrm{~mm})$. The filtrate was later transferred into a crucible and evaporated into dryness over water bath and weighed to a constant weight.

\section{Result}

The phytochemical analysis revealed the presence of Tannin, saponin, flavonoid, steroid, terpernoids, cardiac glycoside, alkaloid and phenol as shown in Table 1. The percentage composition of the phytochemcial constituents of Aframomum melegueta is shown in Table 2. The results showed that the extracts from Aframomum melegueta have antimicrobial activity against all the isolates tested even at lower concentration.

At $5 \mathrm{mg} / \mathrm{ml}$ concentrations of both the ethanolic and aqueous extract, there are zones of inhibition, but the ethanolic extract showed greater antimicrobial activity than the aqueous extract as indicated by zones of inhibition in (Table 3) and (Table 4).

The largest zones of inhibition occurred with Escherichia coli, Salmonella spp and Klebsiella spp which indicated that, they were more sensitive to the effect of the extract than the other organisms.

Echerichia coli \& Klebsiella spp showed highest zones of inhibition at high concentration of $50 \mathrm{mg} / \mathrm{mg}$. At $5 \mathrm{mg} / \mathrm{ml}$ concentration, the ethanolic extract is effective on both salmonella spp and shigella spp but at $50 \mathrm{mg} / \mathrm{ml}$, the ethanolic extract is effective on all the isolates. This indicates that the antimicrobial activity of this plant is concentration dependent. Ethanolic extract showed high inhibitory zones than aqueous extracts. This indicates that ethanol is a better extract than distilled water.

\section{Discussion}

The result of this work showed that the seed extract of Aframomum melegueta inhibited the growth of all the bacteria tested (Table $3 \& 4$ ). This suggests that the plant extract is broad spectrum in activity. Higher antimicrobial activity of the extracts was observed on E.coli, Klebsiella spp and Salmonella spp at high concentration, this is similar to the earlier result obtained by (Oyagade, 1999), (Akpulu, 1994) and (Oladunmoye, 2007). The antimicrobial effect of Aframomum melegueta is due to the phytochemical constituents present in it. Aframomum melegueta seeds are rich in phytonutrient such as flavonoids, phenolic compound tannins, saponin, terpernoids, cardiac glycosides and alkaloids.

The biological function of flavonoids includes protection against allergies, inflammation, free radicals, platelet aggregation, microbes, ulcers, hepatoxins, viruses and tumors (Okwu, 2004). This may be the reason behind the use of the extracts of this plant in the treatment of intestinal troubles in herbal medicine. (Okwu, 2004). The presence of phenolic compounds in the seed of Aframomum melegueta indicates that this plant might be an antimicrobial agent. This is because phenols and phenolic compounds have been extensively used in disinfection and remain the standard with which other bactericides are compared. Phenolic compounds as electron donors are readily oxidized to form phenolate ion or quinine, an electron acceptor. This gives rise to practical uses. Protonated phenol is used as cleaning agent. Extracts from Aframomum melegueta therefore have potent antiseptic or bactericidal properties. (Okwu, 2004). This finding supports the use of extracts from Aframomum melegueta in treating wounds that not only heals fast but also prevents the formation of infections (Okwu, 2004). The presence of phenol further indicated that the seed of this plant could act as anti inflammatory, anti clotting, antioxidant, immune enhancers and hormone modulators. This plant also has quantity of saponin content. Some of the general characteristics of saponin include formation of foam in aqueous solutions, hemolytic activity cholesterol binding properties and bitterness (Okwu, 2004). Apart from saponin other metabolite constituents of Aframomum melegueta detected include the alkaloids and tannin. Alkaloids ranked the most efficient therapeutically significant plant substance. Pure isolated plant alkaloids and their synthetic derivatives are used 
as basic medicinal agents for their analgesic, antispasmodic and bactericidal effects. They exhibit marked physiological activity when administered to animals. The high tannin content could be partly responsible for the hot, bitter and pungenty taste of Aframomum melegueta seed. Tannin has a stringent property; it hastens the healing of wounds and inflamed mucous membrane (Okwu and Okwu., 2004). The presence of tannin in this plant strongly supports its use in treating wounds, burns and hemorrhoids in herbal medicine. The aqueous extract was found to be bacteriostatic. While ethanolic extract was bactericidal at higher concentrations. The presence of phytochemcial supports its uses as antimicrobial agent

\section{Conclusion}

The plant Aframomum melegueta can be of immense use in phytomedicine and can be included in health care delivery system particularly in the developing economies. Further studies on more effective method of extracting only the necessary constituents and standard reconstitution means as well as other processing, refining and purification measures would be necessary. It can be concluded from this study that the extracts from the seed of Aframomum melegueta showed antimicrobial activity against the tested isolates at high concentration of $50 \mathrm{mg} / \mathrm{ml}$.This probably justifies its use as an antimicrobial agent.

\section{References}

Akpulu, I.N., Dada, J.D., Odama, E.L and Galadima, O. (1994). Anti Bacterial activity of aqueous extracts of some Nigerian medicinal plants. Nigerian Journal of Botany, 7:45-48.

Boham, B.A., Kocipai-Abyazan, R. (1974). Flavonoids and condensed tannis from leaves of Hawallan vaccinium vaticultum and $V$. calycinium. Journal of pacific science, 48: 458-463.

Edeoga, H.O., Okwu, D.E. and Mbaeble, B.O. (2005). Phytochemical Constituents of some Nigerian Medicinal Plants. African Journal of Biotechnology, 4: 685-688.

Galal, A. M. (1996). Antimicrobial activity of 6-paradol and related Compounds. International Journal of Pharmacognosy, 31: 37-43.

Harbone, J.B., (1973). Phytochemical methods, London, Chapman and Hall, Ltd. 188pp

Hazan, A.G. and Atta, R. (2005). Trends in Ethnopharmacology. Journal of Ethnopharmacology, 100:43-49.

Lino, A. and Deogracious, O. (2006). The invitro antibacterial activity of Annonna senegalensis, Sacuridecae longipendiculata and Steganotaema araliacea. Uganda medicinal plants. Journal of African Health Science, 6(1):31-35

Obadoni, B.O., Ochuko, P.O. (2001). Phytochemcial studies and comparative efficacy of the crude extracts of some homostatic plants in Edo and Delta States of Nigeria. Global Journal of Pure Applied Science, 7(3): 455-459.

Okwu, D.E. (2001). A improving Nutritive value of cassava Tapiocmeal with local spices. Journal of Nutraceutical, Functional and medical food, 3:43-51

Okwu, D.E. (2004). Phytochemicals and vitamin content of Indigenous spices of South Eastern Nigeria. Journal of Sustain Agricultural environment, 6: 30-34

Okwu, D.E and Okwu, M.E. (2004). Chemical composition of Spondias mombia Linn plant parts. Journal of Sustain Agricultural environment, 6: 140-147.

Okwu, D.E. (2005). Phytochemicals, Vitamins and Mineral contents of two Nigeria Medicinal Plants. International Journal of Molecular Medicine and Advance Sciences, 1 (4):375-381

Oladunmoye, M.K. and Dada, E.O. (2007). Comparative studies on the Antimicrobial activity of leafs extracts from Aframomum melegueta. Research Journal of Botany, 2(2): 95-107

Oyagade, J.O., Awotoye, O.O., Adewunmi, J.T., and Thorpe, H.T., (1999) Antimicrobial activity of some Nigerian medicinal Plants, screening for antibacterial activity. Journal of Bioscience research Communication, 11:193-197.

Rios, J.L. and Recio, M.C. (2005). Medicinal plants and Antimicrobial activity. Journal of Enthopharmacology, 100: 80

Sofowora, A. (1993). Medicinal plants and Traditional Medicine in Africa. Spectrum Books Limited, Ibadan, Nigeria.346pp.

Van-Burden, T.P., Robinson, W.C. (1981). Formation of complexes between protein and Tannin acid. Journal of Agriculture and Food Chemistry. 
Table 1. Phytochemical constituents of the seeds of Aframomum melegueta

\begin{tabular}{|l|l|}
\hline Constituents & Results \\
\hline Tannin & + \\
\hline Saponin & + \\
\hline Flavonoid & + \\
\hline Steroid & + \\
\hline Terpernoids & + \\
\hline Cardiac glycoside & + \\
\hline Alkaloid & + \\
\hline Phlobatannis & - \\
\hline
\end{tabular}

$+=$ present, $-=$ Not present

Table 2. Percentage composition of the Phytochemical constituents of seeds of Aframomum melegueta

\begin{tabular}{|l|l|}
\hline Constituents & Results \\
\hline Phenol & 0.83 \\
\hline Alkanoids & 1.14 \\
\hline Tannins & 17.21 \\
\hline Flavonoids & 0.54 \\
\hline Saponin & 1.40 \\
\hline
\end{tabular}

Table 3. Zones of inhibition of ethanolic extracts of the seed of Aframomum melegueta

Mean Zones of inhibition (mm)

\begin{tabular}{|l|l|l|l|l|l|}
\hline Isolates & $50 \mathrm{mg} / \mathrm{ml}$ & $30 \mathrm{mg} / \mathrm{ml}$ & $20 \mathrm{mg} / \mathrm{ml}$ & $10 \mathrm{mg} / \mathrm{ml}$ & $5 \mathrm{mg} / \mathrm{ml}$ \\
\hline Salmonella spp & 15 & 15 & 12 & 9 & 9 \\
\hline Escherichia coli & 20 & 10 & 8 & NIL & NIL \\
\hline Klebsiella spp & 30 & 15 & 14 & NIL & NIL \\
\hline Shigella spp & 12 & 12 & 10 & 10 & 9 \\
\hline
\end{tabular}

Mean Zones of inhibition in millimeters,

NIL $=$ No inhibition

Table 4. Zones of inhibition of aqueous extracts of the seed of Aframomum melegueta

Mean Zones of inhibition (mm)

\begin{tabular}{|l|l|l|l|l|l|}
\hline & $50 \mathrm{mg} / \mathrm{ml}$ & $30 \mathrm{mg} / \mathrm{ml}$ & $20 \mathrm{mg} / \mathrm{ml}$ & $10 \mathrm{mg} / \mathrm{ml}$ & $5 \mathrm{mg} / \mathrm{ml}$ \\
\hline Isolates & & & & & \\
\hline Salmonella spp & 10.5 & 9.0 & 9.0 & 8.0 & 7.0 \\
\hline Escherichia coli & 10.0 & 9.0 & 9.0 & 8.0 & 8.0 \\
\hline Klebsiella spp & 13.0 & 9.0 & 8.0 & 8.0 & 8.0 \\
\hline Shigella spp & 12.0 & 9.0 & 9.0 & 9.0 & 8.0 \\
\hline
\end{tabular}

